\title{
Milk fermented by Lactobacillus gasseri SBT2055 influences adipocyte size via inhibition of dietary fat absorption in Zucker rats
}

\author{
Essam M. Hamad ${ }^{1,2}$, Masao Sato ${ }^{1}$, Kazunori Uzu ${ }^{1}$, Takeshi Yoshida ${ }^{1}$, Seiichiro Higashi ${ }^{1}$, \\ Hiroshi Kawakami ${ }^{3}$, Yukio Kadooka ${ }^{3}$, Hiroaki Matsuyama ${ }^{3}$, Ibrahim A. Abd El-Gawad ${ }^{2}$ \\ and Katsumi Imaizumi ${ }^{1 *}$ \\ ${ }^{1}$ Laboratory of Nutrition Chemistry, Faculty of Agriculture, Graduate School, Kyushu University, Fukuoka 812-8581, Japan \\ ${ }^{2}$ Dairy Science and Technology Department, Faculty of Agriculture, Cairo University, Giza 12613, Egypt \\ ${ }^{3}$ Technology and Research Institute, Snow Brand Milk Products Co. Ltd, Saitama 350-1165, Japan \\ (Received 6 March 2008 - Revised 15 May 2008 - Accepted 30 May 2008 - First published online 7 August 2008)
}

\begin{abstract}
We have demonstrated previously that a diet containing skimmed milk (SM) fermented by Lactobacillus gasseri SBT2055 (LGSP) reduces adipocyte size in Sprague-Dawley rats. Two experiments were conducted to extend these observations in order to elucidate the mechanism involved. In experiment 1, lean and obese Zucker rats were fed a diet containing SM or LGSP for 4 weeks. The LGSP diet, compared with the SM diet, resulted in lowering of the mesenteric adipose tissue weight $(23 \% ; P<0.05)$, adipocyte sizes $(28 \% ; P<0.001)$ and serum leptin concentration $(36 \% ; P<0.05)$ in lean rats. Obese Zucker rats did not display such dietary effects. Only the number of smaller adipocytes was increased $(P<0.05)$ by the LGSP diet in the subcutaneous adipose tissue of obese rats. The LGSP diet significantly reduced the serum and hepatic cholesterol in rats. In addition, the LGSP diet led to an increased excretion of faecal fatty acids and total neutral faecal sterols in both rat strains. In experiment 2, Sprague-Dawley rats with permanent cannulation of the thoracic duct were fed either the SM or LGSP diets and their lymph was collected. The LGSP diet lowered the maximum transport rate of TAG and phospholipids. These results indicate that fermented milk regulates adipose tissue growth through inhibition at the stage of dietary fat absorption in lean Zucker rats.
\end{abstract}

Lactobacillus gasseri: Zucker rats: Adipocyte size: Lymph lipids: Faecal fatty acids

Recently, the use of probiotic strains (particularly lactobacilli and bifidobacteria) has been promoted because of their potential therapeutic effects, which have been studied extensively ${ }^{(1,2)}$. Lactobacillus gasseri, previously classified as L. acidophilus, is considered as a major species of human flora. There are many reports revealing the potential beneficial effects of $L$. gasseri, including immunomodulatory properties $^{(3)}$, enhancement of intestinal functions ${ }^{(4)}$, hypocholesterolaemic effect ${ }^{(5)}$ and inhibitory action against undesirable bacteria $^{(6)}$.

L. gasseri SBT2055 is one of the strains that was isolated at the Technical Research Institute of Snow Brand Milk Products Co., Ltd (Kawagoe, Japan) from human infant or adult faeces $^{(7)}$. This strain has the ability to reach and establish in the intestine in both man and mice ${ }^{(8)}$. Therefore, this strain was chosen as an excellent probiotic strain due to its suitability as a starter for preparing fermented milk $^{(9)}$.

The adipose tissue expansion that occurs during the development of obesity is initially characterised either by an increase in fat cell size or by an increase in fat cell number. A recent study in our laboratory has shown that a fermented milk product containing L. gasseri SBT2055 (LGSP) exerts a beneficial effect on the onset of obesity by lowering adipocyte size and the level of leptin in Sprague-Dawley rats ${ }^{(10)}$. Although the mechanism of this effect of fermented milk on adipocyte size has not been elucidated, it is likely that LGSP may affect adipocyte size through inhibition of energy input. In fact, it was found that inhibitors of lipid absorption affect the body fat mass through increased excretion of faecal lipids ${ }^{(11)}$. Furthermore, L. gasseri strains have been reported to bind micellar lipids, thereby raising a possibility of inhibiting the absorption of fatty acids and cholesterol $^{(12)}$.

Because Sprague-Dawley rats are relatively lean, it is necessary to use an obese animal model for further studies. Zucker obese rats show early-onset, extreme obesity due to leptin receptor deficiency ${ }^{(13)}$ and overeating ${ }^{(14,15)}$. Therefore, Zucker obese rats are often used as an animal model of hyperphagia and hyperlipidaemia. Accordingly, Zucker obese rats may provide a better model to further clarify the effects of L. gasseri SBT2055-fermented milk on adipocyte size.

In the present study, we studied whether LGSP has an effect on adiposity parameters in obese as well as lean Zucker rats. Simultaneously, faecal fatty acid excretion was determined in these Zucker rats in order to clarify the underlying mechanism of altered adiposity parameters. Moreover, we directly determined the effect of the LGSP diet on lymphatic lipid absorption by Sprague-Dawley rats with cannulated thoracic lymph ducts. 


\section{Materials and methods}

Preparation of the milk product fermented by Lactobacillus gasseri SBT2055

LGSP was prepared by fermenting skimmed milk (SM) using L. gasseri SBT2055 (this strain was isolated and classified by DNA homology analysis at the Technical Research Institute of Snow Brand Milk Products Co., Ltd, Kawagoe, Japan ${ }^{(9)}$ ) as described previously ${ }^{(10,16)}$. Briefly, SM powder (Snow Brand Milk Products, Co., Ltd, Tokyo, Japan) was hydrated with deionised water, added to a yeast extract, and sterilised at $95^{\circ} \mathrm{C}$ for $30 \mathrm{~min}$. After inoculation with L. gasseri SBT2055, the $\mathrm{SM}$ was incubated at $37^{\circ} \mathrm{C}$ for $16 \mathrm{~h}$. The fermented product containing the bacterial cells was freeze dried (in order to retain bacterial viability ${ }^{(17)}$ ) and used for subsequent experiments. SM powder was also treated in a similar manner without inoculation and used as a control (non-fermented $\mathrm{SM})$. The chemical composition of SM $(34.7 \%$ protein, $0.9 \%$ fat, $52.6 \%$ carbohydrate, $7.9 \%$ ash, $3.9 \%$ moisture) and fermented SM $(35.4 \%$ protein, $0.9 \%$ fat, $52.6 \%$ carbohydrate, $7.7 \%$ ash, $3.4 \%$ moisture) was almost the same. The latter also contained $11.8 \mathrm{~g}$ lactic acid/100 $\mathrm{g}$. In addition, the concentration of viable $L$. gasseri in the final fermented milk-containing diet was $6 \times 10^{7}$ colony-forming units per $g$ diet.

\section{Animals and diets}

Two experiments were carried out in accordance with the Guidelines for Animal Experiments of the Faculty of Agriculture and the Graduate Course of Kyushu University, Fukuoka, Japan, and law no. 105 and Notification no. 6 of the government of Japan. In both experiments, all rats were allowed free access to commercial chow for 1 week and then housed individually in stainless steel cages in an air-conditioned room $\left(21-24^{\circ} \mathrm{C}\right.$, lights on from 08.00 to 20.00 hours).

\section{Experiment 1}

Zucker lean and obese rats, age 5 weeks, were obtained from Japan SLC, Inc. (Shizuoka, Japan). They were divided into two groups (eight rats per group) for each rat strain. One group in each rat strain was fed the SM-containing diet as a control group, and the other group was fed the L. gasseri STB2055-fermented milk-containing diet. Experimental diets were prepared according to the AIN-76 formula ${ }^{(18)}$ with some modifications, containing (g/kg): 70 fat (maize oil), $200 \mathrm{SM}$ powder or fermented milk powder, 125 casein, $150 \alpha$-maize starch, 50 cellulose, 3 DL-methionine, 35 mineral mixture (AIN-76), 10 vitamin mixture, and sucrose to $1000 \mathrm{~g}$. The diets containing SM powder and fermented milk powder were designated as the SM and LGSP diets, respectively. The quantity of protein supplied from the fermented and non-fermented SM powder was 70.8 and $69.4 \mathrm{~g} / \mathrm{kg}$ diet, respectively. The rats were allowed free access to the experimental diets and water for 4 weeks, and their body weight was monitored. The rats were killed by withdrawing blood from the abdominal aorta under diethyl ether anaesthesia. Faeces were collected for the last $3 \mathrm{~d}$ of the feeding period and kept at $-20^{\circ} \mathrm{C}$ until analysis. The liver and white adipose tissues from mesenteric, perirenal, retroperitoneal, epididymal, and subcutaneous (depots extended from the dorsolumbar area to the gluteal with an intermediate region located in the inguinal area) regions were excised and weighed. The liver was kept at $-20^{\circ} \mathrm{C}$ until analysis.

\section{Experiment 2}

Male Sprague-Dawley rats, aged 5 weeks, were obtained from Japan Kyudo Co. Ltd (Saga, Japan). The animals were divided into two groups (six rats per group). One group was fed the SM diet as a control group, and the other group was fed the LGSP diet. The rats were trained to consume the experimental diets twice per $\mathrm{d}$ from 10.00-11.00 and 16.00-17.00 hours, respectively, for 1 week. Deionised water was freely available throughout the feeding periods.

On the day of surgery, all rats were anesthetised with Nembutal before permanent cannulation of the thoracic duct according to a method modified by our laboratory ${ }^{(19)}$. Briefly, a cannula (Silicon tube $\mathrm{SH}$, internal diameter $0.5 \mathrm{~mm}$ and outside diameter $1.0 \mathrm{~mm}$; Kaneka Medics Co., Tokyo, Japan) filled with heparinised saline was inserted into the thoracic duct and secured within the abdominal cavity. After surgery, the rats were returned to their cages and provided with the experimental diets twice per $\mathrm{d}$. On the third postoperative day, the rats were attached to a long PE-cannula (internal diameter $0.58 \mathrm{~mm}$ and outside diameter $0.97 \mathrm{~mm}$; Becton-Dickinson Co., Cockeysville, MD, USA) to collect lymph samples. The end of the cannula was $5-10 \mathrm{~cm}$ below the bottom of the cage to provide sufficient underside pressure to allow the lymph to enter the cannula. The lymph was collected for $30 \mathrm{~min}$ as the blank and the rats were then given free access to the experimental diet for $30 \mathrm{~min}$. After provision of the experimental diet, lymph was collected every hour for $7 \mathrm{~h}$ in separate tubes. The rats freely consumed deionised water during lymph collection.

During the experiment, the growth parameters were monitored. At the end of the lymph collection period, the rats were killed by withdrawing blood from the abdominal aorta under diethyl ether anaesthesia. The obtained lymph samples were analysed for total cholesterol, TAG and phospholipids.

\section{Methods of analysis}

Analyses of lipids, glucose and adipocytokines. The concentrations of serum TAG, total cholesterol, HDL-cholesterol, phospholipids and glucose were measured using enzyme assay kits (Triglyceride E test, Phospholipids C test and Glucose C test from Wako Pure Chemicals, Osaka, Japan and Determiner TC555 from Kyowa Medix, Tokyo, Japan). Serum adiponectin and leptin concentrations were measured using ELISA kits (Mouse/rat adiponectin ELISA kit from Otsuka Pharmaceutical, Tokyo, Japan and rat leptin ELISA from Yanaihara Institute, Shizuoka, Japan). Liver lipids were extracted by the method of Folch et al. ${ }^{(20)}$ and the concentration of TAG, total cholesterol and phospholipids was measured ${ }^{(10)}$.

Measurement of lipoprotein lipase activity in adipose tissue. In accordance with the method of Perona \& Ruiz-Gutierrez ${ }^{(21)}$, subcutaneous adipose tissue $(0 \cdot 5-1 \mathrm{~g})$ was homogenised with $40 \mathrm{ml}$ cooled acetone $\left(-20^{\circ} \mathrm{C}\right)$, filtered through Whatman no. 2 filter paper, and washed with $20 \mathrm{ml}$ cooled acetone, $40 \mathrm{ml}$ acetone at room temperature and $40 \mathrm{ml}$ diethyl ether. After drying, the remaining powder was weighed and stored at $-80^{\circ} \mathrm{C}$ until use. Ammonium buffer (1 ml; $25 \mathrm{~mm}$; pH 8.1) 
containing 1 unit/ml of sodium heparin was added to $5 \mathrm{mg}$ of the powder. The mixture was incubated on ice for $60 \mathrm{~min}$ and subsequently centrifuged at $5000 \mathrm{~g}$ for $10 \mathrm{~min}$ at $4^{\circ} \mathrm{C}$. The supernatant fraction was employed as a lipoprotein lipase (LPL) source. One sample was used for the activity measurement and another sample for protein quantification according to the method of Lowry et al. ${ }^{(22)}$. Dibutyryl fluorescein (Sigma, St Louis, MO, USA) was prepared as a substrate for the reaction with LPL by dissolving $1 \mathrm{mg}$ in $5 \mathrm{ml}$ ethylene glycol monomethyl ether. Of this solution, $1 \mathrm{ml}$ was dissolved in $20 \mathrm{ml}$ of $0.1 \mathrm{M}$-phosphate buffer $(\mathrm{pH} 8)$. Of the enzyme extract, $200 \mu \mathrm{l}$ were incubated $\left(37^{\circ} \mathrm{C}\right.$ for $\left.20 \mathrm{~min}\right)$ with $1500 \mu \mathrm{l}$ dibutyryl fluorescein solution, $150 \mu$ l ethylene glycol monomethyl ether and $1250 \mu \mathrm{l}$ phosphate buffer. LPL activity was quantified as the difference between the fluorescence emitted by the released fluorescein when $1 \mathrm{M}-\mathrm{NaCl}$ was added to the incubation medium and the level emitted in the absence of $\mathrm{NaCl}$. Fluorescence was measured in a fluorescence spectrophotometer (Shimadzu Dual beam difference spectrofluorophotometer RF-520; Seisakusho Ltd, Kyoto, Japan) with excitation at $490 \mathrm{~nm}$ and emission at $530 \mathrm{~nm}$.

Measurement of adipocyte cell size. Adipocyte cell size in the mesenteric and subcutaneous adipose tissue was measured as described previously ${ }^{(10)}$. In short, adipose tissues rinsed with saline solution were fixed in $10 \%$ neutral formalin-buffered solution, embedded in paraffin, cut into $10 \mu \mathrm{m}$ sections, and stained with haematoxylin. Cell sizes were measured using National Institutes of Health (Bethesda, MD, USA) image software (100 cells per rat).

Analysis of faecal fatty acids and sterols. Faeces were lyophilised and faecal fatty acids were analysed by the method of Van de Kamer et al. ${ }^{(23)}$ as modified by Jeejeebhoy et al. ${ }^{(24)}$. The apparent excretion rate of dietary fat per $\mathrm{d}$ was calculated as follows: $100 \times$ (amount of faecal fatty acids excreted)/ (amount of daily fat intake).

Faecal neutral sterols were derivatised to trimethylsilyl ethers, and faecal acidic sterols were methylated and derivatised to trimethylsilyl ethers. The products were analysed by gas-liquid chromatography (GC-17A Shimadzu; Seisakusho Ltd, Kyoto, Japan) using $5 \alpha$-cholestane (Nacalai Tesque, Kyoto, Japan) and 23-nordeoxycholic acid (Steraloids, Inc., Wilton, NH, USA) as internal standards for neutral sterols and bile acids, respectively ${ }^{(25)}$.

Analysis of lymph lipids. Lymph lipid levels were measured using commercially available enzyme assay kits (Triglyceride E test and Phospholipids C test from Wako Pure Chemicals, Osaka, Japan; Determiner TC555 from Kyowa Medix, Tokyo, Japan) as described previously ${ }^{(10)}$.

\section{Statistical analysis}

The data were expressed as mean values with their standard errors. The effects of diet (SM $v$. LGSP) and genotype (lean $v$. obese) were analysed by two-way ANOVA. Data for which the variances were unequal were logarithmically transformed before ANOVA or post hoc analysis. When the effect of diet or its interaction with genotype in ANOVA resulted in a significant $F$ test, Student's $t$ test was used for comparisons between the two groups of each genotype. However, the cell size for adipocytes of each size (Figs. 1 and 2) was statistically analysed only by Student's $t$ test between the two groups of each genotype because of the large difference (more than three times) in the average adipocyte size between the genotypes (Table 1). In the second experiment, Student's $t$ test was used for analysing data. Differences were considered statistically significant for $P \leq 0 \cdot 05$. The analysis was carried out with Excel 2002 (Microsoft Corp., Redmond, WA, USA).

\section{Results \\ Experiment 1}

Body and organ weights as well as several metabolic and morphometric parameters were determined in all rat groups (Table 1). The obese Zucker rats had a higher average food intake and body-weight gain compared with the lean rats $(P<0.001)$. Food intake per d was similar between LGSPand SM-fed groups in each rat strain. Body-weight gain was not affected by diet. The LGSP diet resulted in an increased relative liver weight in both lean and obese rats compared with the SM diet $(P<0 \cdot 001)$.

The weight of individual adipose tissues and the total weight were greater in the obese rats than in the lean rats $(P<0.001)$. The LGSP diet resulted in reduced total, mesenteric and subcutaneous adipose tissue masses $(P<0.05)$, whereas no significant effect was noticed on other white adipose tissues. In lean rats the mesenteric fat mass was significantly reduced by the LGSP diet $(22 \% ; P<0.05)$ more prominently than in obese rats. The size of mesenteric and subcutaneous adipocytes was greater in the obese rats compared with the lean rats $(P<0.001)$. While there was no effect of diet on the average size of subcutaneous adipocytes, there was a significant effect of diet $(P<0.05)$ and genotype $\times$ diet interaction $(P<0.001)$ on the average size of mesenteric adipocytes. Student's $t$ test showed that the LGSP diet was associated with a reduction in average adipocyte size in mesenteric adipose tissue in lean rats $(28 \% ; P<0.001)$ but not in obese rats.

Likewise, the numbers of smaller adipocytes increased while the numbers of large adipocytes decreased in the mesenteric and subcutaneous tissues of lean and obese rats, respectively, when they were fed the LGSP-containing diet (Figs. 1 and 2). On the contrary, there was no significant effect of the LGSP diet on the profile of the distribution of adipocyte size in mesenteric adipose tissue of obese rats or from subcutaneous adipose tissue of lean rats (Figs. 1 and 2).

LPL activity in the subcutaneous adipose tissue was greater in the obese rats compared with the lean rats $(P<0.001)$. There was a significant effect $(P<0.05)$ of genotype $\times$ diet interaction on the LPL activity in the subcutaneous adipose tissue of Zucker rats (Table 1). This significant effect was attributed to a tendency towards decreased LPL activity $(P=0 \cdot 07)$ in obese rats fed the LGSP diet.

The concentration of serum leptin and adiponectin was greater in the obese rats compared with the lean rats $(P<0.001)$. In addition, there was a significant effect $(P<0.05)$ of the LGSP diet on serum leptin concentrations (Table 1). The leptin levels in the serum of lean rats were decreased $(36 \% ; P<0.05)$ by the LGSP diet. In contrast, there was no effect of the LGSP diet on the serum levels of both glucose and adiponectin in Zucker rats (Table 1). 

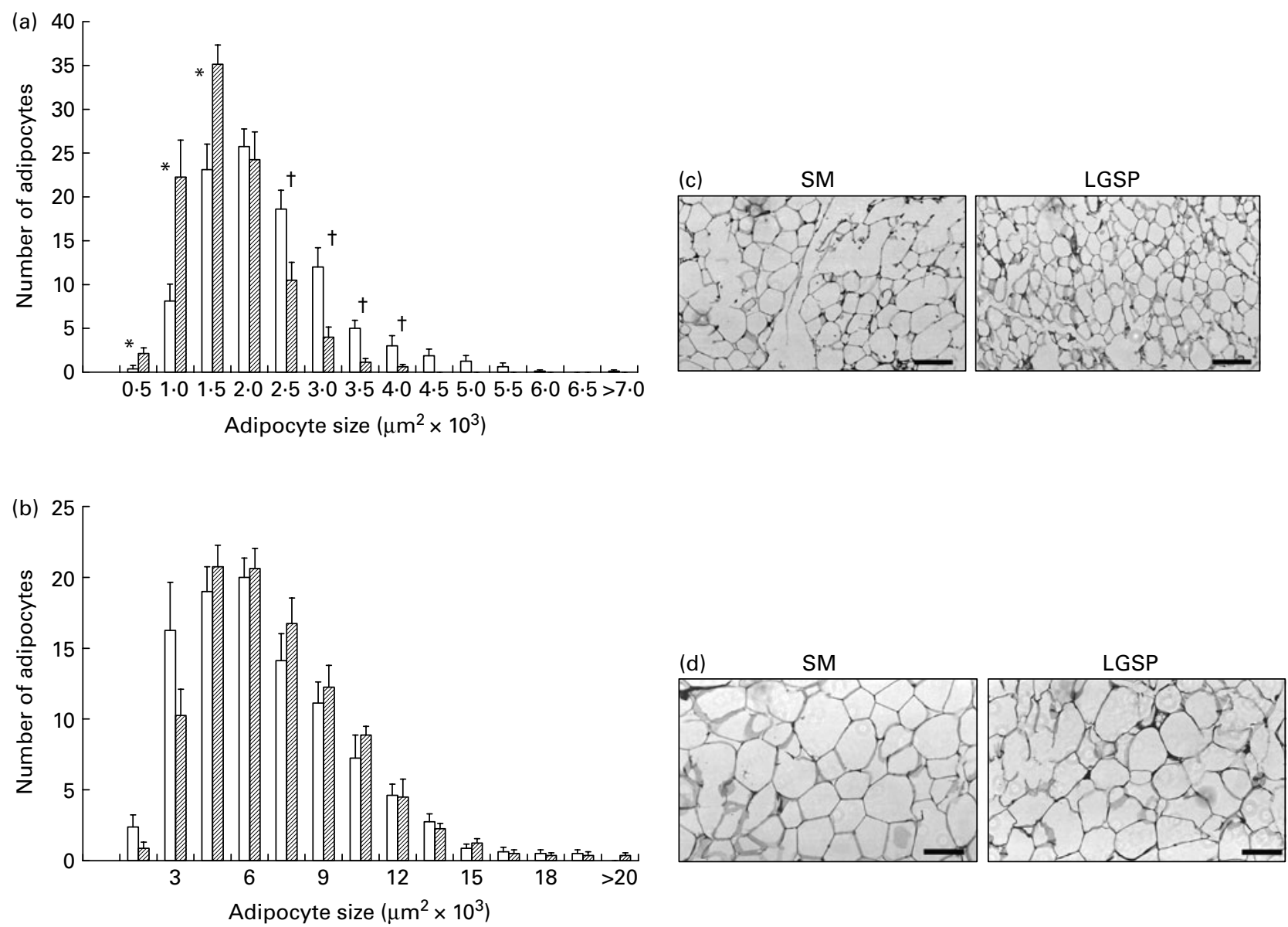

Fig. 1. The effect of dietary skimmed milk (SM) and Lactobacillus gasseri-fermented milk product (LGSP) on cell size in mesenteric adipose tissue. Profile of the distribution of cell size of adipocytes from lean (a) and obese (b) Zucker rats (SM, $\square$; LGSP, (2). Values are means for eight rats per group, with their standard errors represented by vertical bars. * Mean value for small adipocytes was significantly higher in the LGSP group than in the SM group $(P<0.05)$. $†$ Mean value for large adipocytes was significantly lower in the LGSP group than in the SM group $(P<0.05)$. Adipocytes in paraffin sections (scale bar: $100 \mu \mathrm{m})$ of lean (c) and obese (d) Zucker rats.

The concentrations of serum lipids were higher in the obese rats relative to the lean rats (Table 1). Moreover, rats fed the LGSP diet displayed a significant reduction in the levels of total and HDL-cholesterol in their serum $(P<0 \cdot 05)$, whereas there was no significant effect of diet on the remaining serum lipids (Table 1). The concentration of liver TAG was remarkably greater in the obese rats compared with the lean rats $(P<0.001)$. Genotype significantly affected the liver cholesterol $(P<0.05)$ and phospholipid $(P<0.01)$ levels. In addition, the LGSP diet reduced the level of hepatic phospholipids and cholesterol $(P<0.05)$, with no effect on the level of hepatic TAG (Table 1).

Faecal weight was greater in the obese rats compared with the lean rats (Table 2) $(P<0 \cdot 001)$. Faecal weight was significantly greater $(P<0.05)$ in the LGSP group than in the SM group. The amount of faecal fatty acids was greater in the obese rats compared with the lean rats $(P<0 \cdot 001)$, but there was no significant difference between the strains in terms of the apparent excretion rate. The LGSP diet resulted in a significant $(P<0.01)$ increase in the amount of faecal NEFA and the apparent excretion of NEFA in the faeces of both Zucker rat strains (Table 2). The faecal excretion of cholesterol $(P<0.01)$, coprostanol $(P<0.05)$ and total neutral sterol $(P<0 \cdot 001)$ (Table 2$)$ was influenced by the strain. The LGSP diet resulted in a significant $(P<0.05)$ increase in faecal cholesterol (Table 2). There was a significant effect $(P<0 \cdot 05)$ of genotype $\times$ diet interaction on total neutral sterols in the obese rats. The amount of faecal total bile acid and individual components (lithocholic, deoxycholic, chenodeoxycholic, hyodeoxycholic, ursodeoxycholic and $\beta$-muricholic acid) was greater in the lean rats compared with the obese rats $(P<0.001)$ (Table 2$)$. In addition, the LGSP diet significantly increased the deoxycholic acid $(P<0.05)$ and decreased $\beta$-muricholic acid $(P<0.01)$ levels in the obese rats. There was a significant effect $(P<0 \cdot 01)$ of genotype $X$ diet interaction on the excretion of ursodeoxycholic acid. There was no significant effect of the LGSP diet on the excretion of total acidic sterols.

\section{Experiment 2}

Food consumption by the rats within the feeding period did not differ between the two groups (11.3 (SE 0.3) and 10.5 (SE 0.9) $\mathrm{g} / \mathrm{d}$ for the SM and LGSP diets, respectively). Lymph flow also did not differ between the two groups (data not shown). The maximum transport rates (after $4 \mathrm{~h}$ 

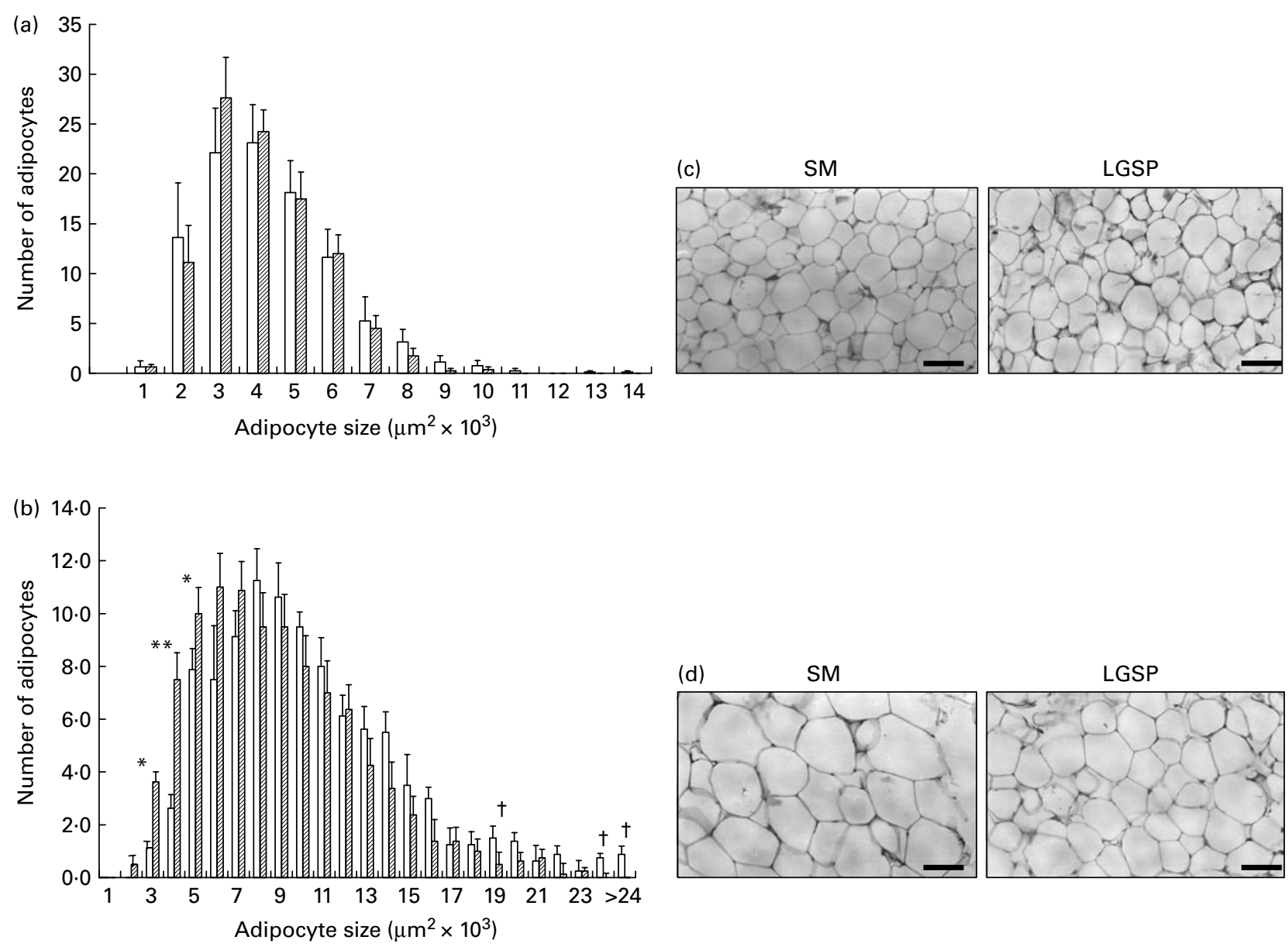

Fig. 2. The effect of dietary skimmed milk (SM) and Lactobacillus gasseri-fermented milk product (LGSP) on cell size in subcutaneous adipose tissue. Profile of the distribution of cell size of adipocytes from lean (a) and obese (b) Zucker rats (SM, $\square$; LGSP, 固). Values are means for eight rats per group, with their standard errors represented by vertical bars. ${ }^{*}$ Mean value for small adipocytes was significantly higher in the LGSP group than in the SM group $(P<0.05)$. $†$ Mean value for large adipocytes was significantly lower in the LGSP group than in the SM group $(P<0.05)$. Adipocytes in paraffin sections (scale bar: $100 \mu \mathrm{m})$ of lean (c) and obese (d) Zucker rats.

lymph collection) of both TAG and phospholipids were lower in the LGSP group than in the SM group (Fig. 3). The maximum transport rate of cholesterol tended to be lower in the LGSP group than in the SM group $(P=0 \cdot 06)$.

\section{Discussion}

In Zucker rats fed a diet containing milk fermented by L. gasseri SBT2055 (LGSP) there was a reduction in the fat mass, adipocyte size and leptin levels and an increase in the faecal fatty acid content. Moreover, there was a significant effect of the LGSP diet on the maximum absorption of lymphatic lipids in Sprague-Dawley rats. This is the first report showing that a fermented milk product containing L. gasseri SBT2055 affects adipocyte size in Zucker rats and lymphatic lipid absorption in Sprague-Dawley rats. These findings suggest a close relationship between adipocyte size and fatty acid absorption in Zucker rats.

In the present study, the size and mass of mesenteric adipose tissue were significantly reduced (28 and $23 \%$, respectively) by feeding the LGSP diet to lean Zucker rats, but there was almost no effect on the mesenteric adipose tissue of obese Zucker rats. In contrast, the LGSP diet resulted in a decreased mass of subcutaneous adipose tissue in Zucker rats compared with the SM diet. In particular, the number of smaller adipocytes was increased in the subcutaneous adipose tissue of obese rats fed on the LGSP diet. These results indicate that the LGSP diet led to changes in mesenteric and subcutaneous adipose tissues. The effect of diet observed in the lean Zucker rats is very similar to that observed in our previous study in Sprague-Dawley rats ${ }^{(10)}$. This similarity may be because the growth of the adipose tissue in lean Zucker rats is quite similar to that reported for Sprague-Dawley rats ${ }^{(26)}$.

Similarly, there was a prominent reduction in the serum levels of leptin in lean rats fed the LGSP diet but not in obese Zucker rats. In fact, the serum level of leptin is correlated with adipose tissue weight or adipocyte size in both rodents $^{(27)}$ and humans ${ }^{(28)}$. Therefore, the lower serum level of leptin in the LGSP group of lean Zucker rats may reflect the reduction of the fat mass and adipocyte size of their mesenteric adipose tissue. Despite the increase in the number of smaller adipocytes in subcutaneous depots in obese Zucker rats (Fig. 2), no change was noted in their serum leptin levels. This is likely to be due to the lower contribution of subcutaneous adipose tissue to the expression of 
Table 1. Effect of skimmed milk (SM) and Lactobacillus gasseri-fermented milk product (LGSP) on morphometric and metabolic parameters in lean and obese Zucker rats (Mean values with their standard errors for eight rats per group)

\begin{tabular}{|c|c|c|c|c|c|c|c|c|c|c|c|}
\hline & \multicolumn{4}{|c|}{ Lean } & \multicolumn{4}{|c|}{ Obese } & & & \\
\hline & \multicolumn{2}{|c|}{ SM } & \multicolumn{2}{|c|}{ LGSP } & \multicolumn{2}{|c|}{ SM } & \multicolumn{2}{|c|}{ LGSP } & \multicolumn{3}{|c|}{$P($ ANOVA) } \\
\hline & Mean & SE & Mean & SE & Mean & SE & Mean & SE & Genotype & Diet & Genotype $\times$ diet \\
\hline Food intake (g/d) & $15 \cdot 0$ & 0.3 & $14 \cdot 7$ & 0.1 & $21 \cdot 4$ & 0.2 & $21 \cdot 3$ & 0.1 & 0.001 & NS & NS \\
\hline Body-weight gain (g) & 123 & 3 & 115 & 2 & 184 & 3 & 184 & 4 & 0.001 & NS & NS \\
\hline Relative liver weight ( $\mathrm{g} / 100 \mathrm{~g}$ body weight) & 3.26 & 0.02 & $3.53^{\star \star}$ & 0.02 & $3 \cdot 61$ & 0.06 & $3.97^{\star *}$ & 0.07 & 0.001 & 0.001 & NS \\
\hline Mesenteric fat mass $(\mathrm{g})$ & 1.83 & 0.14 & $1.41^{*}$ & 0.12 & 7.73 & 0.26 & $7 \cdot 54$ & 0.12 & 0.001 & 0.05 & NS \\
\hline Perirenal fat mass $(\mathrm{g})$ & 0.61 & 0.07 & 0.49 & 0.05 & $2 \cdot 25$ & $0 \cdot 11$ & $2 \cdot 37$ & $0 \cdot 10$ & 0.001 & NS & NS \\
\hline Retroperitoneal fat mass (g) & $2 \cdot 23$ & 0.19 & 1.82 & $0 \cdot 18$ & 7.97 & 0.25 & $7 \cdot 56$ & 0.09 & 0.001 & NS & NS \\
\hline Epididymal fat mass $(\mathrm{g})$ & $2 \cdot 39$ & 0.09 & $2 \cdot 22$ & 0.15 & 8.75 & 0.21 & $8 \cdot 49$ & $0 \cdot 17$ & 0.001 & NS & NS \\
\hline Subcutaneous fat mass (g) & 8.24 & 0.76 & $6 \cdot 75$ & 0.53 & 36.07 & 1.27 & $33 \cdot 66$ & 1.21 & 0.001 & 0.05 & NS \\
\hline Total fat mass $(\mathrm{g})$ & $15 \cdot 30$ & $1 \cdot 19$ & $12 \cdot 69$ & 0.95 & $62 \cdot 76$ & 1.35 & 59.63 & 1.52 & 0.001 & 0.05 & NS \\
\hline Mesenteric adipocyte size $\left(\mu \mathrm{m}^{2} \times 10^{3}\right)$ & $2 \cdot 01$ & 0.11 & $1 \cdot 44^{\star \star *}$ & 0.08 & $6 \cdot 02$ & 0.37 & $6 \cdot 38$ & 0.21 & 0.001 & 0.05 & 0.001 \\
\hline Subcutaneous adipocyte size $\left(\mu \mathrm{m}^{2} \times 10^{3}\right)$ & 3.83 & 0.43 & 3.65 & 0.21 & 9.83 & 0.43 & 8.30 & 0.21 & 0.001 & NS & NS \\
\hline $\begin{array}{l}\text { Lipoprotein lipase activity in subcutaneous adipose } \\
\text { tissue (nmol/min per mg protein) }\end{array}$ & 0.224 & 0.030 & 0.338 & $0 \cdot 067$ & $0 \cdot 727$ & $0 \cdot 122$ & 0.449 & 0.076 & 0.001 & NS & 0.05 \\
\hline Serum leptin (ng/l) & 11.0 & 1.0 & $7 \cdot 0^{*}$ & 1.0 & $149 \cdot 5$ & $5 \cdot 0$ & $129 \cdot 6$ & $13 \cdot 2$ & 0.001 & 0.05 & NS \\
\hline Serum adiponectin ( $\mu \mathrm{g} / \mathrm{ml})$ & $8 \cdot 3$ & 0.5 & $7 \cdot 8$ & 0.5 & $13 \cdot 0$ & 0.4 & $12 \cdot 7$ & 0.4 & 0.001 & NS & NS \\
\hline Serum glucose $(\mathrm{mg} / \mathrm{l})$ & 1870 & 80 & 1810 & 60 & 1810 & 50 & 1780 & 50 & NS & NS & NS \\
\hline \multicolumn{12}{|l|}{ Serum lipids (mg/l) } \\
\hline TAG & 1440 & 110 & 1260 & 150 & 2990 & 160 & 3410 & 240 & 0.001 & NS & NS \\
\hline Phospholipids & 1570 & 50 & 1570 & 40 & 3130 & 60 & 3240 & 60 & 0.001 & NS & NS \\
\hline Total cholesterol & 795 & 28 & 726 & 15 & 1600 & 40 & 1480 & 30 & 0.001 & 0.05 & NS \\
\hline HDL-cholesterol & 563 & 16 & $493^{*}$ & 11 & 994 & 32 & 946 & 41 & 0.001 & 0.05 & NS \\
\hline \multicolumn{12}{|l|}{ Liver lipids (mg/g) } \\
\hline TAG & 8.9 & 0.9 & $8 \cdot 2$ & 0.6 & $76 \cdot 3$ & $16 \cdot 5$ & $78 \cdot 6$ & $12 \cdot 0$ & 0.001 & NS & NS \\
\hline Phospholipids & 31.8 & 0.4 & 30.9 & 0.6 & $30 \cdot 1$ & 0.7 & 28.4 & 0.7 & 0.01 & 0.05 & NS \\
\hline Cholesterol & $2 \cdot 2$ & 0.0 & $2 \cdot 1$ & 0.0 & $2 \cdot 2$ & $0 \cdot 1$ & $1.9^{*}$ & 0.1 & 0.05 & 0.05 & NS \\
\hline
\end{tabular}

Mean value was significantly different from that of the rats fed the SM diet: ${ }^{\star} P<0.05,{ }^{\star \star} P<0.01,{ }^{\star \star \star} P<0.001$ (Student's $t$ test). 
Table 2. Effect of skimmed milk (SM) and Lactobacillus gasseri-fermented milk product (LGSP) on faecal steroid composition in lean and obese Zucker rats

(Mean values with their standard errors for eight rats per group)

\begin{tabular}{|c|c|c|c|c|c|c|c|c|c|c|c|}
\hline & \multicolumn{4}{|c|}{ Lean } & \multicolumn{4}{|c|}{ Obese } & & & \\
\hline & \multicolumn{2}{|c|}{ SM } & \multicolumn{2}{|c|}{ LGSP } & \multicolumn{2}{|c|}{ SM } & \multicolumn{2}{|c|}{ LGSP } & \multicolumn{3}{|c|}{$P($ ANOVA) } \\
\hline & Mean & SE & Mean & $\mathrm{SE}$ & Mean & SE & Mean & SE & Genotype & Diet & Genotype $\times$ diet \\
\hline Faeces dry weight $(\mathrm{g} / \mathrm{d})$ & 1.55 & 0.05 & 1.58 & 0.03 & 2.06 & 0.06 & $2 \cdot 27^{\star}$ & 0.05 & 0.001 & 0.05 & NS \\
\hline Amount of faecal NEFA $(\mathrm{mg} / \mathrm{d})$ & $26 \cdot 13$ & $1 \cdot 17$ & $30 \cdot 29^{*}$ & 1.50 & $36 \cdot 15$ & $2 \cdot 16$ & $43 \cdot 41^{*}$ & $2 \cdot 34$ & 0.001 & 0.01 & NS \\
\hline $\begin{array}{l}\text { Apparent excretion rate of faecal NEFA } \\
(\% / d)\end{array}$ & $2 \cdot 21$ & $0 \cdot 12$ & $2 \cdot 63^{*}$ & $0 \cdot 15$ & $2 \cdot 10$ & $0 \cdot 11$ & $2 \cdot 47^{\star}$ & $0 \cdot 14$ & NS & 0.01 & NS \\
\hline \multicolumn{12}{|l|}{ Neutral steroids (mg/rat per $\mathrm{d}$ ) } \\
\hline Cholesterol & 2.57 & 0.18 & 2.55 & 0.04 & 1.86 & 0.09 & $2 \cdot 38^{*}$ & $0 \cdot 16$ & 0.01 & 0.05 & NS \\
\hline Coprostanol & $2 \cdot 07$ & 0.17 & $2 \cdot 30$ & 0.19 & 1.66 & 0.14 & 1.95 & 0.30 & 0.05 & NS & NS \\
\hline Total & 4.64 & 0.18 & 4.85 & 0.19 & 3.53 & 0.13 & $4.33^{*}$ & 0.25 & 0.001 & 0.05 & 0.05 \\
\hline \multicolumn{12}{|l|}{ Acidic steroids (mg/rat per $\mathrm{d})$} \\
\hline Lithocholic acid & $0 \cdot 19$ & 0.02 & 0.21 & 0.02 & 0.05 & 0.01 & 0.07 & 0.02 & 0.001 & NS & NS \\
\hline Deoxycholic acid & 0.67 & 0.08 & 0.89 & 0.06 & 0.15 & 0.02 & $0.27^{*}$ & 0.05 & 0.001 & 0.05 & NS \\
\hline Chenodeoxycholic acid & 0.05 & 0.01 & 0.06 & 0.01 & ND & & ND & & 0.001 & NS & NS \\
\hline Cholic acid & 0.88 & 0.11 & 0.76 & 0.07 & 0.69 & 0.05 & 0.64 & $0 \cdot 11$ & NS & NS & NS \\
\hline$\alpha$-Muricholic acid & 0.51 & 0.13 & 0.92 & 0.15 & 0.02 & 0.01 & 0.07 & 0.04 & NS & NS & NS \\
\hline Hyodeoxycholic acid & $0 \cdot 19$ & $0 \cdot 10$ & 0.15 & 0.03 & ND & & ND & & 0.001 & NS & NS \\
\hline Ursodeoxycholic acid & $0 \cdot 18$ & 0.03 & 0.17 & 0.01 & 0.05 & 0.01 & 0.01 & 0.01 & 0.001 & 0.01 & 0.01 \\
\hline$\beta$-Muricholic acid & 0.45 & 0.08 & 0.31 & 0.04 & 0.08 & 0.01 & $0.04^{*}$ & 0.01 & 0.001 & 0.01 & NS \\
\hline$\omega$-Muricholic acid & 0.90 & 0.19 & 0.60 & 0.11 & 0.81 & 0.08 & 0.76 & 0.11 & NS & NS & NS \\
\hline Total & 4.01 & 0.29 & 4.06 & 0.08 & 1.85 & 0.10 & $1 \cdot 86$ & $0 \cdot 10$ & 0.001 & NS & NS \\
\hline
\end{tabular}

ND, not detected.

${ }^{*}$ Mean value was significantly different from that of the rats fed the SM diet $(P<0 \cdot 05$; Student's $t$ test $)$.

leptin compared with internal adipose tissues as observed in rodents $^{(29)}$. In contrast to leptin, there was no significant difference in the concentration of serum adiponectin in both lean and obese Zucker rats. The difference in the response of these adipocytokines to the LGSP diet may be due to the amounts produced, which is then reflected by their serum concentration, and is greater for adiponectin $(\mu \mathrm{g} / \mathrm{ml})$ than leptin $(\mathrm{pg} / \mathrm{ml})^{(30)}$. These results in lean rats are in line with our previous study in Sprague-Dawley rats ${ }^{(10)}$.

The specific mechanism(s) by which the LGSP diet exerts these effects on adipose tissue remains unknown. One mechanism of adipocyte size regulation by the LGSP diet could be the suppression of adipocyte hypertrophy. The suppression of adipocyte hypertrophy by the LGSP diet might be accounted for by a reduction in energy input (intestinal absorption of lipids). Therefore, we determined the effect of the LGSP diet on the faecal NEFA levels of both Zucker rat strains. The present study showed that the apparent absorption of dietary fat, based on the faecal NEFA excretion levels, was lower when the rats of both strains were fed on the LGSP diet. This finding may explain the reduction of both fat mass and adipocyte size in the mesenteric and subcutaneous adipose tissues in Zucker rats and particularly in the lean rats. In agreement with the present results, a reduction in both fat mass and adipose tissue accumulation through an elevation of NEFA excretion was found previously in mice ${ }^{(11)}$. Likewise, the LGSP diet decreased the maximum lymphatic absorption of TAG (32\%; $P=0.03)$, phospholipids $(34 \% ; P=0.02)$ and cholesterol $(27 \% ; P=0.06)$ in Sprague-Dawley rats. This reduction in lymphatic lipid absorption may support the elevation of faecal NEFA excretion that was observed in the LGSP groups. This effect of the LGSP diet might be because it has an ability to bind intestinal lipids. It was found that
L. gasseri SBT2055 has the ability to bind intestinal cholesterol $^{(12)}$. In addition, there was a significant genotype $\times$ diet interaction in the present study, which resulted in increased total faecal neutral sterol excretion in Zucker rats. It is likely that the LGSP diet decreased lymphatic lipids absorption via the binding of lipids and consequently decreased the energy input, which affected adipose tissue hypertrophy. This point requires further research in order to elucidate the mechanism involved.

Although the amount of faecal NEFA of obese rats was higher than that of lean rats, there was no effect of diet on the mesenteric adipose tissue mass or adipocyte size in obese rats. It is likely that the effect of the LGSP diet on the increasing excretion of faecal NEFA might be cancelled by the large amount of energy intake by obese Zucker rats (daily food intake is about 1.5 times compared with lean rats). Consequently, the LGSP diet might lead to an insignificant effect on the visceral adipose tissue weight of obese Zucker rats. Strikingly, the number of smaller adipocytes in the subcutaneous adipose tissue of obese Zucker rats was significantly increased $(P<0.05)$ by the LGSP diet. Although the reason for this finding is unknown, there was a significant genotype $\times$ diet interaction on the LPL activity in subcutaneous adipose tissue of Zucker rats. Therefore, the increased number of smaller adipocytes may be attributed to the tendency towards reduced LPL activity in the obese rats $(P=0.073)$. This reason for this finding is currently unclear and further research is required, as we do not have any data concerning the LPL activity in mesenteric adipose tissue due to the low quantity of tissue available from the present study.

The present study showed an increased faecal excretion of neutral sterols and bile acids in lean rats compared with the obese rats. This finding may account for the increased 
(a)

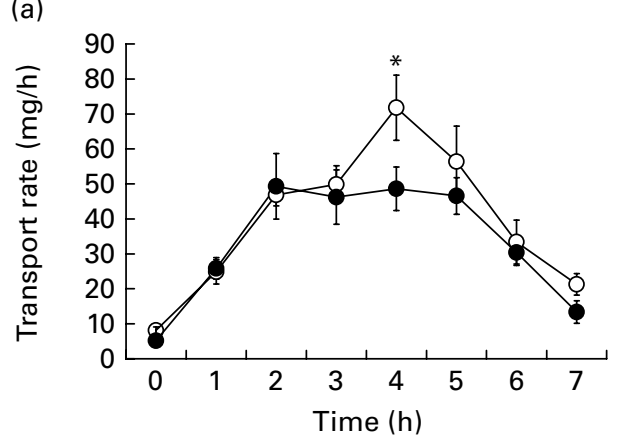

(b)

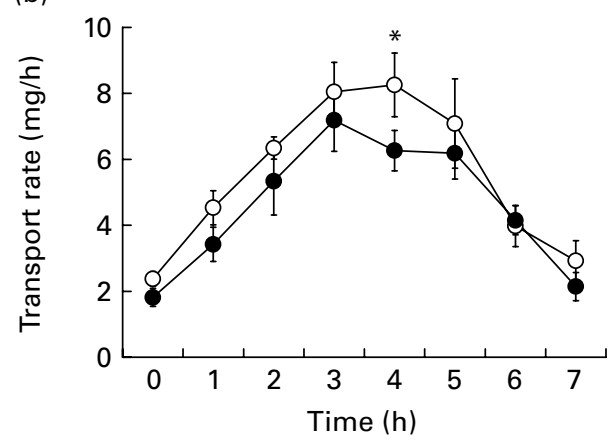

(c)

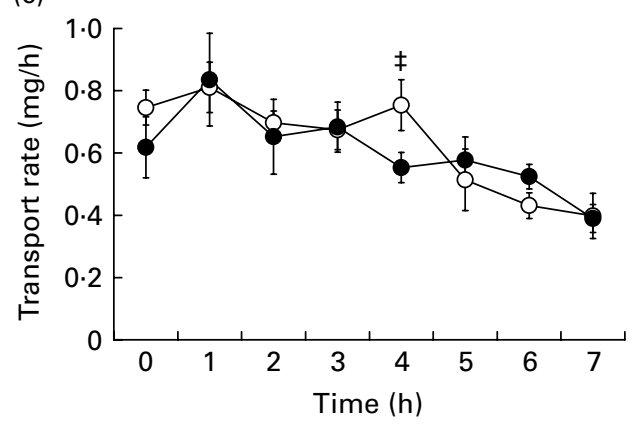

Fig. 3. The effect of dietary skimmed milk (SM) and Lactobacillus gasseri-fermented milk product (LGSP) on the transport of TAG (a), phospholipids (b) and cholesterol (c) in Sprague-Dawley rats with thoracic duct cannulation (SM, O; LGSP, ๑). Values are means for six rats per group, with their standard errors represented by vertical bars. * Mean value was significantly lower in the LGSP group than in the SM group $(P<0.05)$. $¥$ Mean value tended to be lower in the LGSP group than in the SM group $(P=0.06)$.

concentration of serum cholesterol in the obese rats compared with the lean rats, possibly due to the decreased excretion of cholesterol. In addition to these strain differences, the diet also affected the faecal bile acid composition. The LGSP diet tended to elevate the excretion of deoxycholic acid and to lower the excretion of ursodeoxycholic and $\beta$-muricholic acids in Zucker rats. We have no satisfactory explanation for the effect of L. gasseri SBT2055 on the intestinal ecology of our animal models, but this strain might alter the composition and metabolism of the intestinal microflora. Because L. gasseri SBT2055 showed an ability to establish in the intestine of both mice and humans ${ }^{(8)}$, we assumed that it can survive and reach the intestine of our animal models. However, the measurement of the L. gasseri count in the intestine of our animal models should be required to clarify this effect.
In conclusion, the present results indicate that the fermented milk produced by $L$. gasseri SBT2055 may reduce visceral adipose tissue mass and adipocyte hypertrophy in lean Zucker rat via a reduction in fatty acid absorption, but it may have no effect on rats in which obesity is already established. In addition, we do not know if this effect is due to the viable bacterial cells of L. gasseri SBT2055 alone or its milkfermentation products. Therefore, further experiments are needed to explore the factor responsible of this beneficial effect and to elucidate the mechanism(s) involved.

\section{Acknowledgements}

Each author contributed equally to the present work. E. H. received a research scholarship from the government of Egypt; H. K., Y. K. and H. M. are employed by Snow Brand Co. (Saitama, Japan). All costs of analysis were funded by Snow Brand Co., Ltd, and there was no other source of funding. All authors declare no conflicts of interest.

\section{References}

1. Reid G, Jass J, Sebulsky T \& McCormick JK (2003) Potential uses of probiotics in clinical practice. Clin Microbiol Rev 16, 658-672.

2. Saavedra JM (2001) Clinical applications of probiotic agents. Am J Clin Nutr 73, 1147S-1151S.

3. Morita H, He F, Kawase M, Kubota A, Hiramatsu M, Kurisaki J \& Salminen S (2006) Preliminary human study for possible alteration of serum immunoglobulin $\mathrm{E}$ production in perennial allergic rhinitis with fermented milk prepared with Lactobacillus gasseri TMC0356. Microbiol Immunol 50, 701-706.

4. Olivares M, Diaz-Ropero MA, Gomez N, Lara-Villoslada F, Sierra S, Maldonado JA, Martin R, Lopez-Huertas E, Rodriguez JM \& Xaus J (2006) Oral administration of two probiotic strains, Lactobacillus gasseri CECT5714 and Lactobacillus coryniformis CECT5711, enhances the intestinal function of healthy adults. Int $J$ Food Microbiol 107, 104-111.

5. Usman \& Hosono A (2000) Effect of administration of Lactobacillus gasseri on serum lipids and fecal steroids in hypercholesterolemic rats. J Dairy Sci 83, 1705-1711.

6. Zhu WM, Liu W \& Wu DQ (2000) Isolation and characterization of a new bacteriocin from Lactobacillus gasseri KT7. $J$ Appl Microbiol 88, 877-886.

7. Kawai Y, Saito T, Uemura J \& Itoh T (1997) Rapid detection method for bacteriocin and distribution of bacteriocin-producing strains in Lactobacillus acidophilus group lactic acid bacteria isolated from human feces. Biosci Biotechnol Biochem 61, 179-182.

8. Fujiwara S, Seto Y, Kimura A \& Hashiba H (2001) Establishment of orally-administered Lactobacillus gasseri SBT2055SR in the gastrointestinal tract of humans and its influence on intestinal microflora and metabolism. J Appl Microbiol 90, 343-352.

9. Takahashi H, Fujita T, Suzuki Y \& Benn Y (2006) Monitoring and survival of Lactobacillus gasseri SBT2055 in the human intestinal tract. Microbiol Immunol 50, 867-870.

10. Sato M, Uzu K, Yoshida T, Hamad E, Kawakami H, Matsuyama H, Abd El-Gawad I \& Imaizumi K (2008) Effects of milk fermented by Lactobacillus gasseri SBT2055 on adipocyte size in rats. Br J Nutr 99, 1013-1017.

11. Thornton SJ, Warburton C \& Wasan KM (2007) Treatment with a cholesterol absorption inhibitor (FM-VP4) reduces body mass 
and adipose accumulation in developing and pre-obese mice. Drug Dev Ind Pharm 33, 1058-1069.

12. Usman \& Hosono A (1999) Bile tolerance, taurocholate deconjugation, and binding of cholesterol by Lactobacillus gasseri strains. J Dairy Sci 82, 243-248.

13. Zucker LM \& Zucker TF (1961) Fatty, a new mutation in the rat. J Hered 52, 275-278.

14. Bray GA (1977) Zucker fatty rat: a review. Fed Proc 36, 148-153.

15. Meierfrankenfeld B, Abelenda M, Jauker H, Klingenspor M, Kershaw EE, Chua SC Jr, Leibel RL \& Schmidt I (1996) Perinatal energy stores and excessive fat deposition in genetically obese (fa/fa) rats. Am J Physiol 270, E700-E708.

16. Kajimoto O, Hirata H, Aoe S, Takahashi T, Yutaka S \& Tanaka H (2002) Fermented milk containing Lactobacillus gasseri (SP strain) decreases serum cholesterol concentration in men with boundary and mild hypercholesterolemia. Jpn J Lactic Acid Bacteria 13, 114-124.

17. Miyamoto-Shinohara $\mathrm{Y}$, Sukenobe J, Imaizumi $\mathrm{T} \&$ Nakahara $\mathrm{T}$ (2006) Survival curves for microbial species stored by freezedrying. Cryobiology 52, 27-32.

18. Anonymous (1977) Report of the American Institute of Nutrition ad hoc Committee on Standards for Nutritional Studies. J Nutr 107, 1340-1348.

19. Tomoyori H, Kawata Y, Higuchi T, Ichi I, Sato H, Sato M, Ikeda I \& Imaizumi K (2004) Phytosterol oxidation products are absorbed in the intestinal lymphatics in rats but do not accelerate atherosclerosis in apolipoprotein E-deficient mice. J Nutr 134, 2738.

20. Folch J, Lees M \& Sloane Stanley GH (1957) Simple method for the isolation and purification of total lipides from animal tissues. J Biol Chem 226, 497-509.

21. Perona JS \& Ruiz-Gutierrez V (2004) Virgin olive oil normalizes the altered triacylglycerol molecular species composition of adipose tissue in spontaneously hypertensive rats. J Agric Food Chem 52, 4227-4233.

22. Lowry OH, Rosebrough NJ, Farr AL \& Randall RJ (1951) Protein measurement with the Folin-phenol reagents. $J$ Biol Chem 193, 265-275.

23. Van de Kamer JH, ten Bokkel Huinink H \& Weyers HA (1949) Rapid method for the determination of fat in feces. J Biol Chem 177, 347-355.

24. Jeejeebhoy KN, Ahmad S \& Kozak G (1970) Determination of fecal fats containing both medium and long chain triglycerides and fatty acids. Clin Biochem 3, 157-163.

25. Grundy SM, Ahrens EH Jr \& Miettinen TA (1965) Quantitative isolation and gas-liquid chromatographic analysis of total fecal bile acids. J Lipid Res 6, 397-410.

26. Johnson PR, Stern JS, Greenwood MRC \& Hirsch J (1978) Adipose tissue hyperplasia and hyperinsulinemia in Zucker obese female rats: a developmental study. Metabolism 27, Suppl. 2, 1941-1954.

27. Guo KY, Halo P, Leibel RL \& Zhang Y (2004) Effects of obesity on the relationship of leptin mRNA expression and adipocyte size in anatomically distinct fat depots in mice. Am J Physiol Regul Integr Comp Physiol 287, R112-R119.

28. Lönnqvist F, Nordfors L, Jansson M, Thörne A, Schalling M \& Arner P (1997) Leptin secretion from adipose tissue in women: relationship to plasma levels and gene expression. J Clin Invest 99, 2398-2404.

29. Margetic S, Gazzola C, Pegg GG \& Hill RA (2002) Leptin: a review of its peripheral actions and interactions. Int $J$ Obes 26, 1407-1433.

30. Kokkinos A, Mourouzis I, Kyriaki D, Pantos C, Katsilambros N \& Cokkinos DV (2007) Possible implications of leptin, adiponectin and ghrelin in the regulation of energy homeostasis by thyroid hormone. Endocrine 32, 30-32. 